\title{
(2) OPEN ACCESS \\ MRI-based brain volumes of preterm infants at term: a systematic review and meta-analysis
}

\author{
Julia Romberg (D) ,' Marko Wilke, ${ }^{2}$ Christoph Allgaier (D) ,' ${ }^{3}$ Thomas Nägele, \\ Corinna Engel, ${ }^{3}$ Christian F Poets (D) , ${ }^{5}$ Axel Franz (D) ${ }^{5}$
}

\begin{abstract}
- Additional supplemental material is published online only. To view, please visit the journal online (http://dx.doi. org/10.1136/archdischild2021-322846).
\end{abstract}

'Department of Pediatrics, University Hospital Tuebingen, Tuebingen, Germany

${ }^{2}$ Pediatric Neurology \& Developmental Medicine, University Hospital Tuebingen, Tuebingen, Germany

${ }^{3}$ Department of Pediatrics, Center for Pediatric Clinical Studies, University Hospital Tuebingen, Tuebingen, Germany ${ }^{4}$ Department of Neuroradiology, University Hospital Tuebingen, Tuebingen, Germany ${ }^{5}$ Department of Neonatology, University Hospital Tuebingen, Tuebingen, Germany

\section{Correspondence to}

Dr Julia Romberg, Department of Pediatrics, University Hospital Tuebingen, Tuebingen, Germany; julia.romberg@med.unituebingen.de

Received 22 July 2021

Accepted 30 November 2021
ABSTRACT
Background

MRI allows a detailed assessment of brain structures in preterm infants, outperforming cranial ultrasound. Neonatal MR-based brain volumes of preterm infants could serve as objective, quantitative and reproducible surrogate parameters of early brain development. To date, there are no reference values for preterm infants' brain volumes at term-equivalent age. Objective Systematic review of the literature to determine reference ranges for MRI-based brain volumes of very preterm infants at term-equivalent age. Methods PubMed Database was searched on 6 April 2020 for studies reporting MR-based brain volumes on representative unselected populations of very preterm and/or very low birthweight infants examined at term equivalent age (defined as 37-42 weeks mean postmenstrual age at MRI). Analyses were limited to volumetric parameters reported in $>3$ studies. Weighted mean volumes and SD were both calculated and simulated for each parameter.

Results An initial 367 publications were identified. Following application of exclusion criteria, 13 studies from eight countries were included for analysis, yielding four parameters. Weighted mean total brain volume was $379 \mathrm{~mL}$ (SD $72 \mathrm{~mL}$; based on $\mathrm{n=756)}$ ). Cerebellar volume was $21 \mathrm{~mL}(6 \mathrm{~mL} ; \mathrm{n}=791)$, cortical grey matter volume $140 \mathrm{~mL}(47 \mathrm{~mL} ; \mathrm{n}=572$ ) and weighted mean volume of unmyelinated white matter was $195 \mathrm{~mL}$ (38 mL; $\mathrm{n}=499$ ). Conclusion This meta-analysis reports pooled data on several brain and cerebellar volumes which can serve as reference for future studies assessing MRbased volumetric parameters as a surrogate outcome for neurodevelopment and for the interpretation of individual or cohort MRI-based volumetric findings.

\section{INTRODUCTION}

Preterm birth is a major contributor to the global burden of disease. ${ }^{1}$ Neurodevelopmental outcome after preterm birth ultimately determines quality of life; however, the determinants of this outcome are still subject to research. ${ }^{2-5}$

Impaired neurodevelopmental outcome may be present without overt intracerebral lesions detectable by neonatal cranial ultrasound. ${ }^{6}$ In order to identify valid biomarkers that facilitate the prediction of neurocognitive long-term outcome and, at the same time, establish early surrogate endpoints for clinical studies aimed at improving perinatal care, various parameters have been studied on cerebral MRI in preterm infants in the last decades. Of these, advanced methods yielding quantitative parameters (such as volumetric MRI, diffusion

\section{What is already known on this topic?}

- Very preterm and very low birthweight infants show smaller brain volumes compared with term born infants.

- Smaller cerebral volumes in preterm infants are associated with impaired neurocognitive outcome.

- No systematic reference data are available to date regarding brain volumes of very preterm/ very low birthweight infants examined at term.

\section{What this study adds?}

- A systematic search for studies reporting MRbased brain volumes on preterm infants at term equivalent age was performed and weighted means were calculated.

- These could serve as reference data for future studies examining cerebral volumes in preterm infants at term.

MRI, ${ }^{1} \mathrm{H}-\mathrm{MR}$ spectroscopy and resting-state functional connectivity) seem to be most promising for providing objective, predictive and sensitive values.

This systematic review focuses on volumetric MRI, aiming at identifying reference ranges for cerebral and cerebellar volumes in unselected very preterm/very low birthweight (VLBW) infants at term-equivalent age. There is evidence suggesting that reduced brain tissue volumes in preterm infants are associated with impaired neurocognitive outcomes. ${ }^{8-13}$ Reduced cerebral and cerebellar tissue volumes may result from loss of immature oligodendrocytes which are vulnerable to inflammation and fluctuations in haemodynamics and oxygenation eventually resulting in altered cerebral development and impaired function. ${ }^{814-17}$

\section{METHODS}

To identify all published studies reporting brain volume measurements of very preterm or VLBW infants, PubMed was searched on 6 April 2020 using the following systematic search strategy: ('infant, premature' (MeSH) OR 'infant, low birth weight' (MeSH)) AND 'magnetic resonance imaging' (MeSH) AND (volum*(All Fields)). The term 'brain' was intentionally not included in the search strategy to avoid omitting studies focusing on, for example, cerebellar/hippocampal volume 


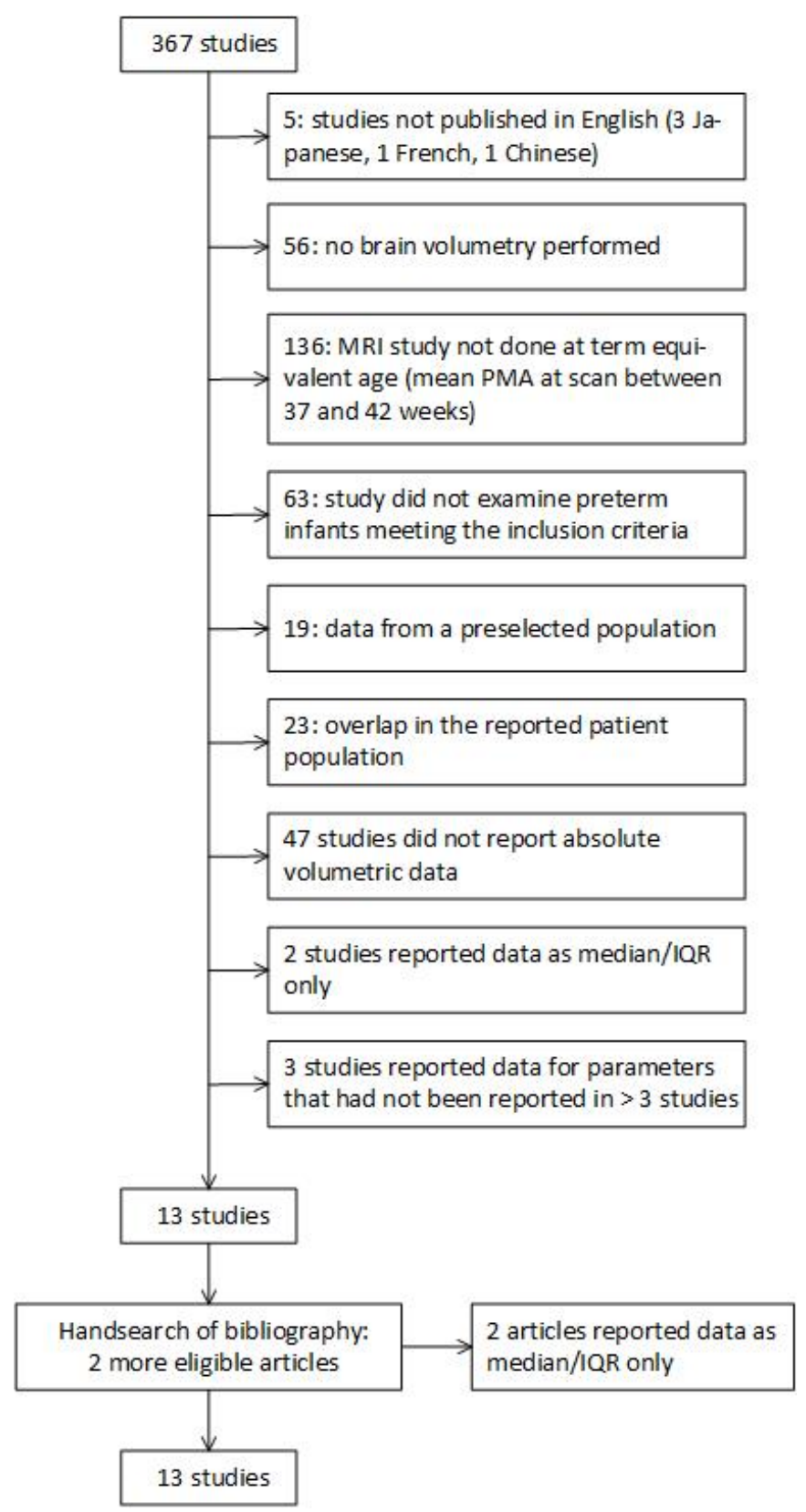

Figure 1 Flow diagram for systematic review of retrieved studies. PMA, postmenstrual age.

measurements. The process of reviewing and assessing studies was based on the guidelines established by Preferred Reporting Items for Systematic Reviews and Meta-Analyses (PRISMA).

Articles were selected for data extraction if they fulfilled all of the following criteria:

- Reporting volumetric data of the brain or its anatomical structures acquired by structural MRI.

- Examining very preterm infants (ie, born at a gestational age $<32$ weeks) or VLBW infants (ie, with birth weight $<1500 \mathrm{~g})$.

- Reporting MRI data acquired at term-equivalent age (ie, if the mean postmenstrual age (PMA) at scan was between 37 and 42 weeks).

- Including representative populations (ie, studies reporting preselected subpopulations were excluded).

- Published in English.
- Accessible (either online, via interlibrary loan, or by directly contacting the authors).

Further,

- If several manuscripts reported data from the same population, only the study including the largest number of infants was included in this review. If there was only a small overlap between patient populations $(<25 \%)$, both studies were included.

- Only brain imaging outcome parameters reported in $>3$ studies were included in the meta-analysis.

First, title and abstract of all articles identified with the search strategy were reviewed manually (by JR and CA) with regard to the above-mentioned inclusion and exclusion criteria, and studies not satisfying these criteria removed. In potentially eligible studies, the full text of each article was reviewed. The bibliography of each eligible full-text article was hand-searched for additional studies. If studies reported concurrent populations of term-born infants, brain volume data were extracted and reported, too.

The following quality criteria were assessed and reported for all eligible studies: Were the infants representative of the underlying population? Was the reliability of image processing methods tested?

Cohorts of included studies were assessed regarding the following characteristics: criteria for inclusion and exclusion in the MRI study, site and time period of recruitment, mean birth weight, mean gestational age at birth, proportion of small for gestational age (SGA) infants, use of antenatal and postnatal steroids, proportion of infants with bronchopulmonary dysplasia (BPD), persistent ductus arteriosus (PDA) and intraventricular haemorrhage (IVH), postmenstrual age (PMA) at MRI scan and type of MRI scanner.

\section{Statistical analyses}

All volumes are reported in millilitres. Gestational age at birth and PMA at MR scan are reported in weeks. In case data had been reported by subgroups, the weighted mean for the overall study population was calculated based on all subgroups.

Meta-analysis of volumetric data was performed in two ways:

(A) Weighted mean values and weighted SD were calculated, the latter on the basis of total variance using SAS statistical software version 9.4:

Total variance: $\mathrm{s}_{\text {total }}^{2}=\frac{1}{n} \sum_{i=1}^{M} n_{i} * s_{i}^{2}+\frac{1}{n} \sum_{i=1}^{N} w_{i} *\left(x_{i}-x^{*}\right)^{2}$

(B) Data from all studies for a given parameter were simulated using the Matlab random number generator (The MathWorks, Natick, Massachusetts, USA): Based on the mean (SD) of a particular study, a total of $\mathrm{n}$ populations with normally distributed 100000 data points each were generated, with $\mathrm{n}$ corresponding to the number of subjects included in the original studies. These synthetic populations of all studies were combined by means of histogram analyses to yield a final population. To this new population (representing all contributing populations in accordance with their original size), we fitted a Gaussian distribution from which a final population mean and SD, as well as a goodnessof-fit parameter was reported.

Linear regression for brain volumes in relation to mean age at scan was calculated and visualised using Python V.3.7 (https:// www.python.org/).

\section{Registration}

This review was not registered. A review protocol was prepared, but not published. 


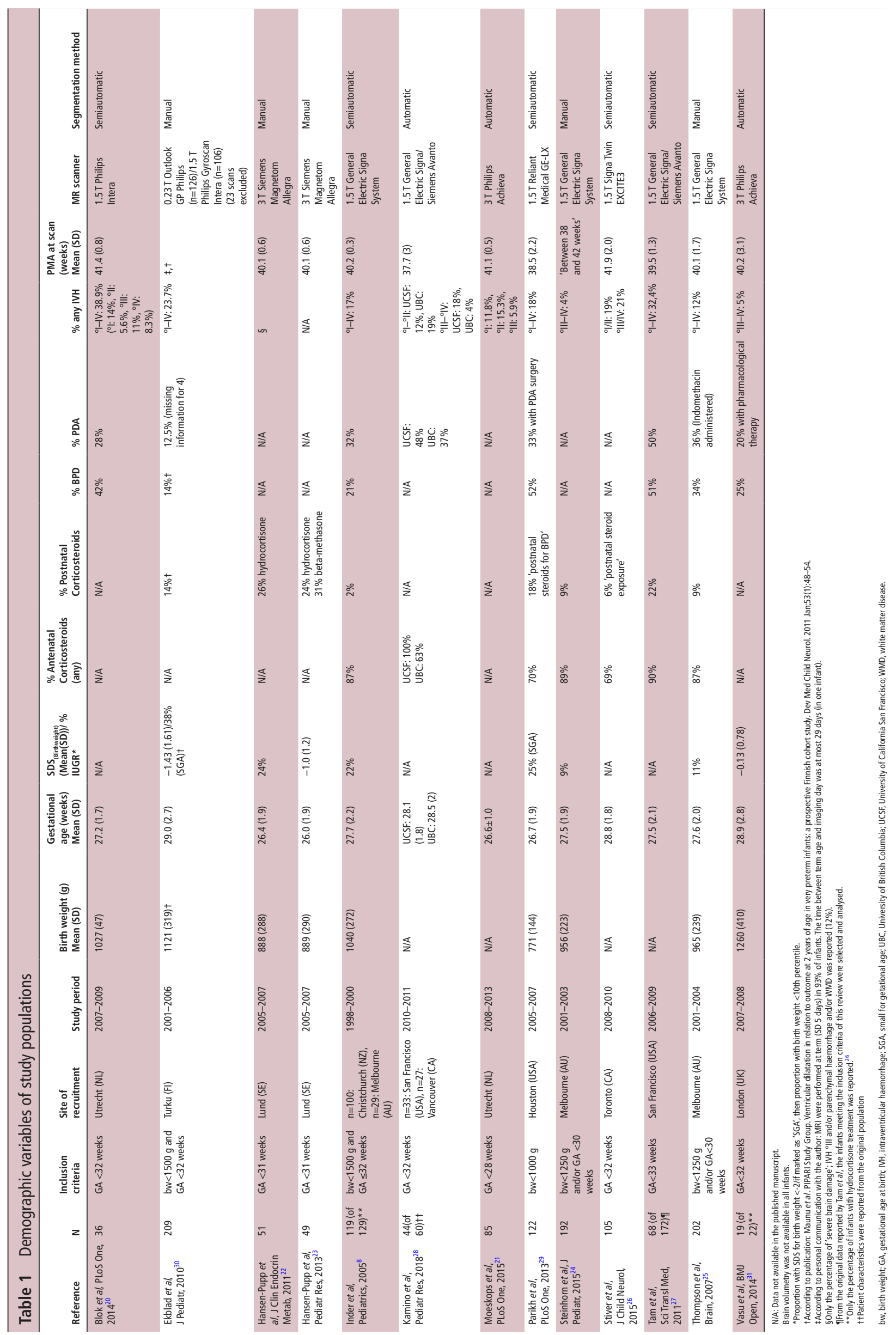


Table 2 Brain volume measurements (and weighted means) in preterm infants at term-equivalent age

\begin{tabular}{|c|c|c|c|c|c|c|}
\hline & $\mathrm{N}$ & $\begin{array}{l}\text { PMA at scan } \\
\text { (weeks) } \\
\text { Mean (SD) }\end{array}$ & $\begin{array}{l}\text { Total brain volume } \\
(\mathrm{mL}) \\
\text { Mean (SD) }\end{array}$ & $\begin{array}{l}\text { Total cerebellar } \\
\text { volume }(\mathrm{mL}) \\
\text { mean }(\mathrm{SD})\end{array}$ & $\begin{array}{l}\text { Cortical grey matter volume } \\
(\mathrm{mL}) \\
\text { Mean (SD) }\end{array}$ & $\begin{array}{l}\text { Unmyelinated white } \\
\text { matter volume (mL) } \\
\text { Mean (SD) }\end{array}$ \\
\hline Blok et al, $2014^{20}$ & 36 & $41.4(0.8)$ & 391 (34) & $\mathrm{N} / \mathrm{A}$ & $\begin{array}{l}167(23)^{*} \\
\text { (overlap with Moeskops et al }{ }^{21}\end{array}$ & $\begin{array}{l}161(21)^{*} \\
\text { (overlap with Moeskops } \\
\text { et } a l^{21} \text { ) }\end{array}$ \\
\hline Ekblad et al, $2010^{30}$ & 209 & $\dagger$ & $397(51.2)$ & $24.2(5.1)$ & $\mathrm{N} / \mathrm{A}$ & N/A \\
\hline Hansen-Pupp et al, $2011^{22}$ & 51 & $40.1(0.6)$ & $\begin{array}{l}396(46.3)^{*} \\
(n=46, \text { overlap with } \\
\left.\text { Hansen-Pupp et } a^{23}\right)\end{array}$ & $21.3(2.7)$ & N/A & $\begin{array}{l}191(25)^{*} \\
(n=46, \text { overlap with } \\
\text { Hansen-Pupp et } \mathrm{al}^{23} \text { ) }\end{array}$ \\
\hline Hansen-Pupp et al, $2013^{23}$ & 49 & $40.1(0.6)$ & $393(50.9)$ & $\begin{array}{l}21.1(3.5)^{*} \\
\text { (overlap with Hansen- } \\
\text { Pupp et al }{ }^{22} \text { ) }\end{array}$ & $\mathrm{N} / \mathrm{A}$ & $190(25)$ \\
\hline Inder et al, $2005^{8}$ & 119 & $40.2(0.3)$ & $406(57)$ & N/A & $178(41)$ & $202(41)$ \\
\hline Kamino et al, $2018^{28}$ & 44 & $37.7(3.0)$ & $\mathrm{N} / \mathrm{A}$ & $16.7(5.3)$ & $107.6(40.2)$ & $151(20.1)$ \\
\hline Moeskops et al, $2015^{21}$ & 85 & $41.1(0.5)$ & $N / A$ & N/A & $107(13)$ & $171(19)$ \\
\hline Parikh et al, $2013^{29}$ & 122 & $38.5(2.2)$ & $270(41.5)$ & $16.1(4.2)$ & $105(19.1)$ & $\mathrm{N} / \mathrm{A}$ \\
\hline Steinhorn et al, $2015^{24}$ & 192 & $\neq$ & $\begin{array}{l}395(63.2)^{*} \text { (overlap } \\
\text { with Thompson et al }{ }^{25} \text { ) }\end{array}$ & $21.4(4.5)$ & $\begin{array}{l}159(41)^{*} \\
\text { (overlap with Thompson et al }{ }^{25} \text { ) }\end{array}$ & $\mathrm{N} / \mathrm{A}$ \\
\hline Stiver et al, $2015^{26}$ & 105 & $41.9(2.0)$ & $\mathrm{N} / \mathrm{A}$ & $23.9(5)$ & $\mathrm{N} / \mathrm{A}$ & $\mathrm{N} / \mathrm{A}$ \\
\hline Tam et al, $2011^{27}$ & 68 & $39.5(1.3)$ & N/A & $20.4(5)$ & $\mathrm{N} / \mathrm{A}$ & $\mathrm{N} / \mathrm{A}$ \\
\hline Thompson et al, $2007^{25}$ & 202 & $40.1(1.7)$ & $395(64)$ & N/A & $159(41)$ & $212(32)$ \\
\hline Vasu et al, $2014^{31}$ & 19 & $40.2(3.1)$ & $462(12.8)$ & N/A & $\mathrm{N} / \mathrm{A}$ & $\mathrm{N} / \mathrm{A}$ \\
\hline \multicolumn{3}{|c|}{$\begin{array}{l}\text { Aggregate data all studies } \\
\text { Weighted mean ( } /(\text { Total variance) })\end{array}$} & 379 (72); n=756 & $21(6) ; n=791$ & 140 (47); $n=572$ & 195 (38); n=499 \\
\hline \multicolumn{3}{|c|}{$\begin{array}{l}\text { Aggregate data all studies } \\
\text { Mean (SD) by simulation }\end{array}$} & $391(67) \S$ & $19(5) \S$ & $135(68) \S$ & $192(38) \S$ \\
\hline \multicolumn{3}{|c|}{$\begin{array}{l}\text { Aggregate data excluding reference } e^{29} \\
\text { Weighted mean ( } /(\text { Total variance) })\end{array}$} & 399 (57) n=634 & $22.3(5.3) n=669$ & $149.2(47.8) n=450$ & $\mathrm{~N} / \mathrm{A}$ \\
\hline
\end{tabular}

${ }^{*}$ Not included in the meta-analysis.

†According to personal communication with the author: 'MRI were performed at term (SD 5 days) in $93 \%$ of infants. The time between term age and imaging day was at most 29 days (in one infant).' Out of 232 total MRI scans, 209 were successfully performed and analysed.

$\ddagger$ Between 38 and 42 weeks.

§Adjusted R² for TBV 0.9850, for CV 0.9965, for CGM 0.8822, for UMWM 0.9906.

CGM, cortical grey matter; CV, cerebellar volume; N/A, not available; PMA, postmenstrual age; TBV, total brain volume; UMWM, unmyelinated white matter.

\section{RESULTS}

Using our initial search criteria, a total of 367 studies, published between 1992 and 2019, were retrieved. After review for inclusion and exclusion criteria, 13 were included (see figure 1). Hand-searching the bibliographies yielded two additional studies meeting the inclusion criteria. ${ }^{18} 19$ However, both could not be included because volume data were reported as median (IQR) and least-squares means, respectively. This left 13 articles for inclusion in the meta-analysis.

We identified potential overlap in populations between studies. ${ }^{20-25}$ In these cases, for each volumetric parameter, only the study with the largest population was included for the respective analysis. A small overlap in the population of two studies ${ }^{825}$ resulted in 29 infants being included twice.

Characteristics of the included study populations are listed in table 1. Studies indicated the following reasons for exclusion of subjects: Major congenital anomalies (stated in 9 out of 13 studies) and low-quality MR images (stated in 5 out of 13 studies). All studies excluded infants with missing parental consent. Three studies additionally excluded infants with congenital infection (no further definition given). ${ }^{26-28}$

Only one study tested representativeness of its study population, and there were no differences between included and excluded subjects regarding gender, multiple birth, gestational age, IVH and BPD. ${ }^{25}$ Some studies indicated recruitment rates in relation to eligible subjects, which varied considerably $\left(90 \% / 80 \%,{ }^{8} 73 \%,{ }^{21} 100 \%,{ }^{29} 66 \%,{ }^{24} 94 \%{ }^{30}\right)$. Most studies $(10 / 13)$ were single-centre cohorts from level III academic centres in highly developed countries.

All studies reported MRI postprocessing and segmentation methods. Except for one study, ${ }^{31}$ all studies specified reliability testing for their technique. Studies employed manual, semiautomated and in three studies, ${ }^{202129}$ automated segmentation techniques (see table 1 ).

\section{Brain volume measurements}

The following volumetric parameters were reported in $>3$ studies: total brain volume (TBV; $\mathrm{n}=756)$, cerebellar volume $(\mathrm{CV} ; \mathrm{n}=791)$, volume of cortical grey matter (CGM; $\mathrm{n}=572)$ and volume of unmyelinated white matter (UMWM; $n=499$ ). Brain volumes are presented in table 2. Figure 2 displays the relation between volume measurements and mean PMA at scan. Simulated populations and fitted Gaussian distribution are depicted in figure 3.

Four studies 8252931 also reported MRI-based brain volumetry in contemporary samples of term-born infants. Results are summarised in online supplemental table S1 and indicate that CGM and UMWM volumes might be reduced by about $25 \%$ in preterm compared with term infants.

Based on the simulated population data, an online supplemental MS-excel spread sheet is provided converting MRI brain volumes of preterm infants into z-scores. 

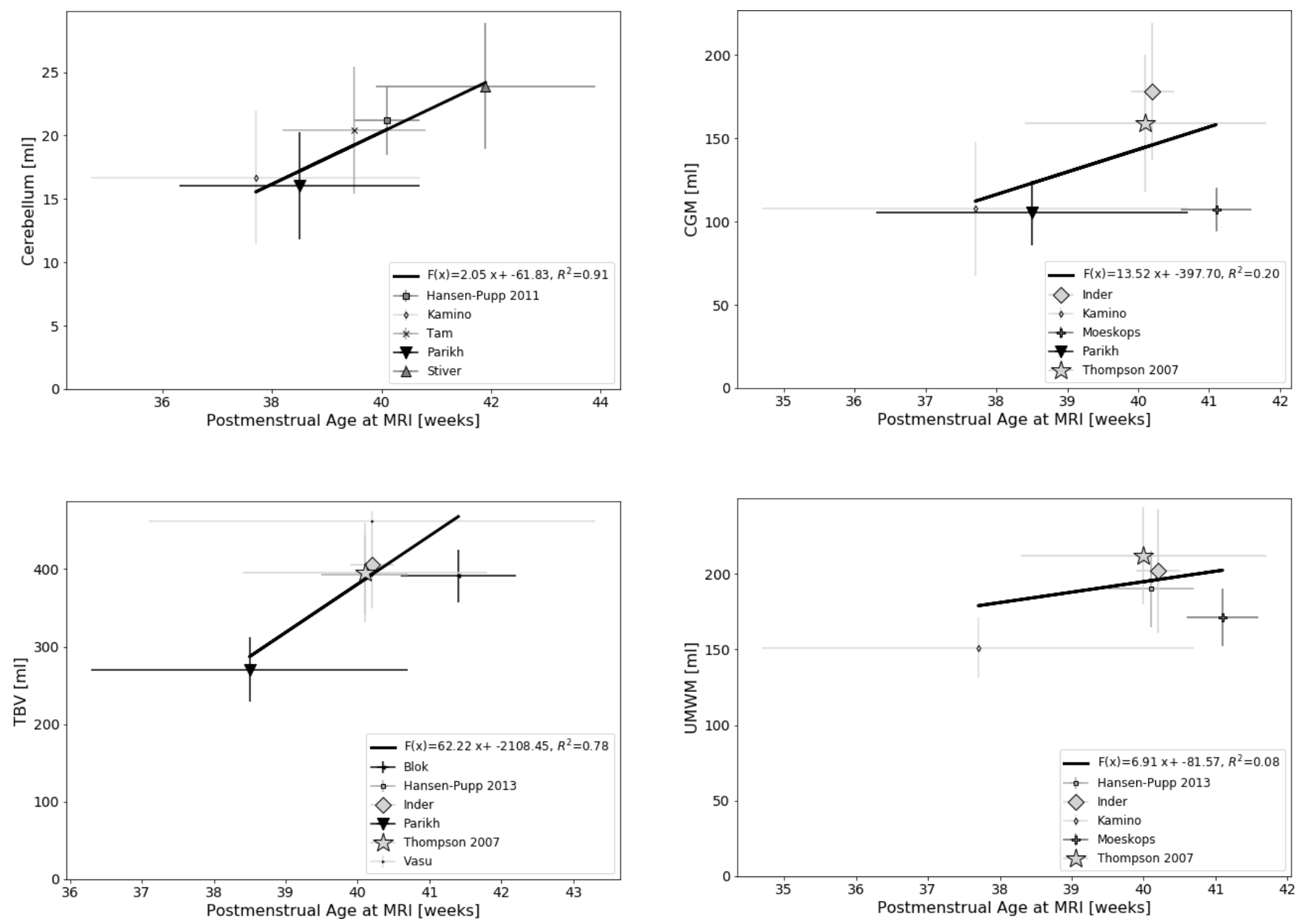

Figure 2 Brain volumes by postmenstrual age (PMA) at MRI scan. CV, cerebellar volume; CGM, cortical grey matter volume; TBV, total brain volume; UMWM, unmyelinated white matter volume. Panels showing mean cerebral volumes according to mean PMA at MRI scan (with horizontal error bars indicating SD for PMA at MRI scan and vertical error bars indicating SD for volume). Sample size for each study is represented by the size of the symbol. Linear regression lines were calculated for each parameter taking sample size into account.

\section{DISCUSSION}

For this systematic review, we identified 13 studies reporting MRI-based brain volume measurements in very preterm infants at term-equivalent age. For TBV, CV, CGM and UMWM, sufficient data were available for this meta-analysis.

All studies included infants with neonatal complications such as BPD, PDA and IVH. Since exclusion criteria of the studies were limited to missing parental consent, 'congenital anomalies' and low-quality MRI images and recruitment rates were $\geq 67 \%$ (reported in six studies), we can assume these study populations to be representative of very preterm infants. However, most studies included single-centre cohorts from academic level III centres in highly developed countries, limiting generalisability to some extent.

In one study, inclusion was restricted to infants $\leq 1000 \mathrm{~g}$ birth weight $^{29}$; consequently, mean birth weight was lower than in the other study populations. Mean TBV, CV and CGM volume all were considerably lower in this cohort compared with the other preterm populations. This discrepancy can partly be attributed to the fact that the timepoint of MRI measurements in this study (mean PMA at scan: $38.5 \pm 2.2$ weeks) was rather early compared with the other studies. Another explanation might be that ELBW infants (i.e. birthweight $<1000 \mathrm{~g}$ ) are more prone to impaired brain growth than VLBW infants; these hypotheses should be tested in future studies or individual patient data metaanalyses. A number of studies (including that of Parikh et $a l^{29}$ ) found smaller brain volumes in IUGR/SGA infants. ${ }^{8} 2225293233$ Notably, Parikh et al also found brain volumes of contemporary term born infants to be markedly smaller compared with those reported by other studies. Thus, a systematic measurement bias could also have contributed to the observed differences. For reference purposes, we also provide the weighted mean and SD values excluding Parikh's study for TBV, CV and CGM volume.

Figure 2 visualises the variance of measured brain volumes among the studies, highlighting the need of large study groups and pooled data. Additionally, linear regression was calculated for brain volumes by PMA at scan showing the best fit for a linear relation for CV. Measurements of $\mathrm{CV}$ could be more reliable due to clear anatomical boundaries, resulting in the lower variability. Furthermore, studies reporting CV were well dispersed for PMA at scan. According to Gui et al, ${ }^{34}$ the cerebellum shows one of the highest growth rates around term, which could explain why a growth trend can be illustrated here. For the other parameters, variance in this restricted time frame is too high to deduce growth trends from the data.

This systematic review and meta-analysis has several limitations: Only one database (PubMed) was searched and only articles in English were included. However, only a very small number 

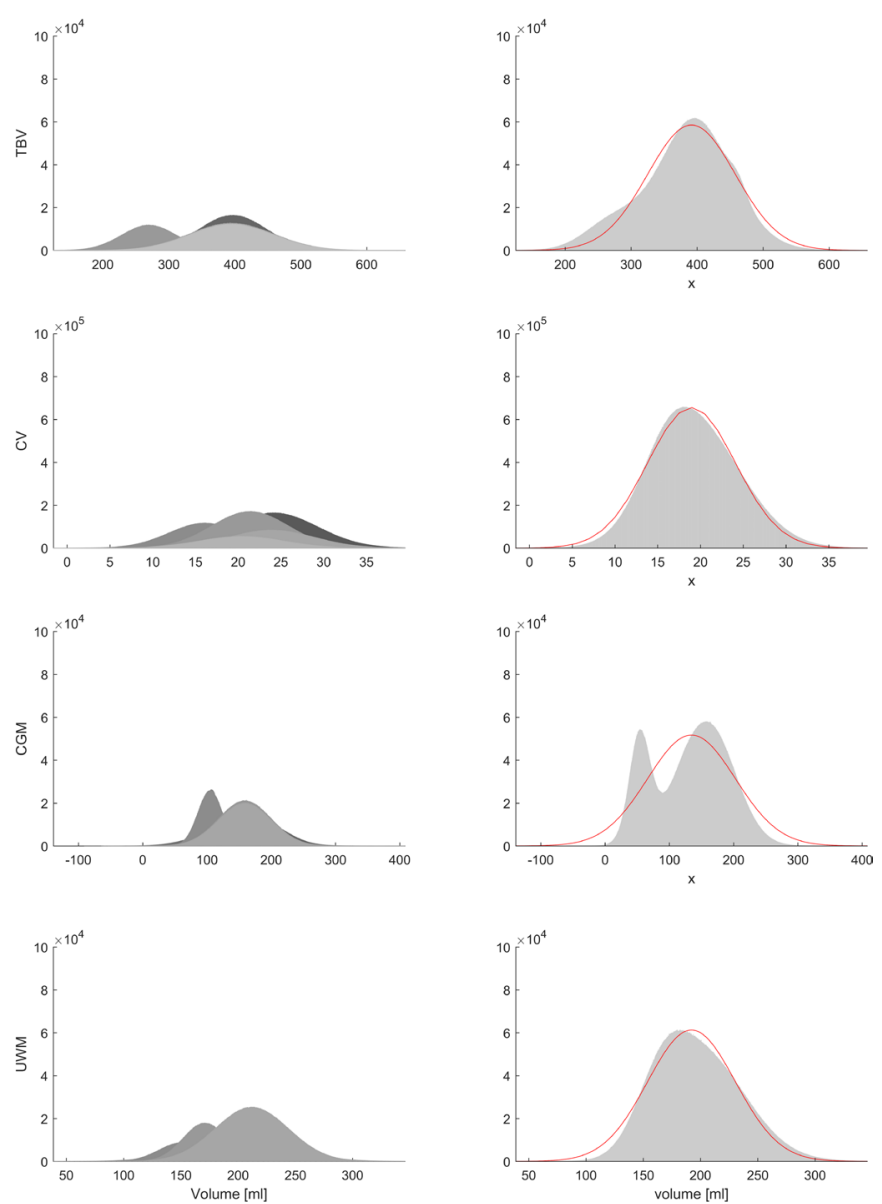

Figure 3 Meta-analysis by simulation studies. CV, cerebellar volume; CGM, cortical grey matter volume; TBV, total brain volume; UMWM, unmyelinated white matter volume. Panels in the left column depict individual synthetic populations (according to simulations described in the Methods section), right column depicts summarising histograms and fitted Gaussian distributions. Resulting means, SDs and $\mathrm{R}^{2} \mathrm{~s}$ are reported in table 2. Figure with permission and created by MW.

(5/367) of initial articles were not published in English and the likelihood that any neonatal volumetric MRI study would not be indexed in PubMed was considered low. Hand-searching the bibliography of all eligible articles also reduced the probability of missing relevant studies.

The number of included studies was relatively low ${ }^{13}$ compared with the number of initially retrieved studies (367). This is due to a combination of relatively strict inclusion criteria and a broad search strategy which retrieved numerous studies in older subjects. Furthermore, studies deviating from our definition of 'term equivalent age' (mean PMA at scan between 37 and 42 weeks) were excluded.

Studies excluding infants with brain lesions (eg, Padilla et $a l^{35}$ ) were not included since our intention was to report on representative preterm infant cohorts. In contrast to our study, Padilla et $a l^{35}$ showed higher mean values in their cohort regarding CGM $(171,2 \mathrm{~mL})$ and the $\mathrm{CV}(26,6 \mathrm{~mL})$. This is consistent with the findings of other studies. ${ }^{36-38}$

Another limitation is that included cohorts ranged from 1998 to 2013, and by our predefined criteria no more recent cohorts were selected, possibly causing bias since both imaging and clinical treatment have evolved. Among the included studies, however, no secular trend could be seen. Furthermore, considerable variability in image acquisition and processing was recognised. For brain volume extraction, tissue segmentation into grey and white matter and cerebrospinal fluid (CSF) is the crucial step. ${ }^{39}$ Of the included studies, five used a manual, five a semiautomatic and three an automatic approach (cf. table 1). All but one study ${ }^{31}$ reported internal validation of their segmentation process. While a congruent approach would of course have been preferable, this (incidentally rather well-balanced) composition makes a substantial bias resulting from our data processing approach unlikely.

Despite heterogeneity concerning study procedures and reporting practices, relatively congruent brain volumes were reported, apart from the ELBW study. ${ }^{29}$ In total, a substantial number of infants could be included in the meta-analysis. It is also reassuring that both methods used to combine the values across populations, despite taking very different approaches, also yielded very similar values (cf. table 2 ). Thus, the resulting mean values and SDs presented in this review can serve as reference data for future volumetric MRI studies among preterm infants and can be consulted when interpreting individual or cohort brain volume measurements in VLBW/very preterm infants. As online supplemental data, we provide a calculator embedded within an Excel worksheet for easy comparison of individual versus these group values.

Ultimately, brain volumes of term born infants should serve as reference for regular, intrauterine brain growth. However, despite all efforts, there is still a gap between cohorts of term born and very preterm infants. In 4 of 13 studies included in this review, concurrent cohorts of term infants were scanned around term-equivalent age, and significantly smaller total brain tissue volumes were demonstrated for preterm infants in all four studies. ${ }^{8252931}$ According to Thompson et al ${ }^{25}$ and Inder et al, ${ }^{8}$ this reduction is driven by smaller CGM and DGM volumes. Furthermore, all four studies revealed significantly increased total CSF volumes in preterm infants, likely reflecting loss or inadequate growth of cerebral tissue (ie, grey or white matter).

Although brain growth of term born infants should be the ultimate goal, brain volume data of unselected very preterms are required when planning interventional studies aiming at optimising brain growth on a realistic basis.

As mentioned above, several studies found an association between birth weight and brain volumes at term. Additionally, male $\operatorname{sex}^{253240}$ and higher gestational age at birth ${ }^{822}$ were found to be associated with larger brain volumes. While it would have been interesting to separate out brain volumes with regard to these factors, the respective data were not available in sufficient detail to allow for their inclusion in multivariate analyses. Future studies on MRI brain volumes in VLBW/very preterm infants should aim at further identifying relevant factors that influence early brain volume growth after preterm birth and, if possible, at quantifying their impact. In this context it would be of special interest to address those factors that are not predetermined (such as sex) but can be modified by optimised neonatal intensive care (such as nutrition, oxygenation, etc). Further studies are also needed that investigate the long-term predictive value of individual MR-based brain volume measurements at term with respect to neurocognitive outcome in childhood and beyond.

In conclusion, in this meta-analysis of 13 studies including data from more than 900 very preterm infants, with the exception of one study, ${ }^{29}$ rather similar results for TBV, CV and UMWM volumes were found at term-equivalent age. These weighted mean volumes may serve as reference for individual patient data and future studies. 
Contributors AF, MW and JR conceived the idea of this systematic review. AF and JR developed the research strategy and criteria of inclusion and exclusion. JR and CA performed the research and selection of studies. AF, MW and JR devised the concept of data extraction, calculation and presentation. MW, CA, CE and JR performed the calculations. JR wrote the manuscript with support of MW, CFP, AF, CA and TN, who all made important intellectual contributions and approved the final version of the manuscript. MW and AF planned and designed the supplemental material. JR acts as guarantor for the study.

Funding The authors have not declared a specific grant for this research from any funding agency in the public, commercial or not-for-profit sectors.

Competing interests None declared.

Patient consent for publication Not applicable.

Ethics approval This study does not involve human participants.

Provenance and peer review Not commissioned; externally peer reviewed.

Data availability statement All data relevant to the study are included in the article or uploaded as supplementary information. The authors confirm that the data supporting the findings of this study are available within the article and/or its supplementary materials.

Supplemental material This content has been supplied by the author(s). It has not been vetted by BMJ Publishing Group Limited (BMJ) and may not have been peer-reviewed. Any opinions or recommendations discussed are solely those of the author(s) and are not endorsed by BMJ. BMJ disclaims all liability and responsibility arising from any reliance placed on the content. Where the content includes any translated material, BMJ does not warrant the accuracy and reliability of the translations (including but not limited to local regulations, clinical guidelines, terminology, drug names and drug dosages), and is not responsible for any error and/or omissions arising from translation and adaptation or otherwise.

Open access This is an open access article distributed in accordance with the Creative Commons Attribution Non Commercial (CC BY-NC 4.0) license, which permits others to distribute, remix, adapt, build upon this work non-commercially, and license their derivative works on different terms, provided the original work is properly cited, appropriate credit is given, any changes made indicated, and the use is non-commercial. See: http://creativecommons.org/licenses/by-nc/4.0/.

\section{ORCID iDs}

Julia Romberg http://orcid.org/0000-0003-3994-0852

Christoph Allgaier http://orcid.org/0000-0001-5577-0801

Christian F Poets http://orcid.org/0000-0002-1072-0066

Axel Franz http://orcid.org/0000-0001-5066-0857

\section{REFERENCES}

1 Blencowe H, Cousens S, Chou D, et al. Born too soon: the global epidemiology of 15 million preterm births. Reprod Health 2013;10 Suppl 1:S2.

2 Saigal S, Doyle LW. An overview of mortality and sequelae of preterm birth from infancy to adulthood. The Lancet 2008:371:261-9.

3 Back SA. Brain injury in the preterm infant: new horizons for pathogenesis and prevention. Pediatr Neurol 2015:53:185-92.

4 Davis AS, Berger VK, Chock VY. Perinatal neuroprotection for extremely preterm infants. Am J Perinatol 2016:33:290-6.

5 Asztalos EV, Church PT, Riley P, et al. Neonatal factors associated with a good neurodevelopmental outcome in very preterm infants. Am J Perinatol 2017;34:388-96.

6 Laptook AR, O'Shea TM, Shankaran S, et al. Adverse neurodevelopmental outcomes among extremely low birth weight infants with a normal head ultrasound: prevalence and antecedents. Pediatrics 2005;115:673-80

7 Parikh NA. Advanced neuroimaging and its role in predicting neurodevelopmental outcomes in very preterm infants. Semin Perinatol 2016;40:530-41.

8 Inder TE, Warfield SK, Wang H, et al. Abnormal cerebral structure is present at term in premature infants. Pediatrics 2005;115:286-94.

9 Peterson BS, Anderson AW, Ehrenkranz R, et al. Regional brain volumes and their later neurodevelopmental correlates in term and preterm infants. Pediatrics 2003:111:939-48.

10 Woodward L, Edgin JO, Thompson D, et al. Object working memory deficits predicted by early brain injury and development in the preterm infant. Brain 2005;128:2578-87.

11 Lind A, Parkkola R, Lehtonen L, et al. Associations between regional brain volumes at term-equivalent age and development at 2 years of age in preterm children. Pediatr Radiol 2011;41:953-61.
12 Rathbone R, Counsell SJ, Kapellou 0, et al. Perinatal cortical growth and childhood neurocognitive abilities. Neurology 2011;77:1510-7.

13 Shah DK, Guinane C, August P, et al. Reduced occipital regional volumes at term predict impaired visual function in early childhood in very low birth weight infants. Invest Ophthalmol Vis Sci 2006;47:3366-73.

14 Buser JR, Segovia KN, Dean JM, et al. Timing of appearance of late oligodendrocyte progenitors coincides with enhanced susceptibility of preterm rabbit cerebral white matter to hypoxia-ischemia. J Cereb Blood Flow Metab 2010;30:1053-65.

15 Back SA. White matter injury in the preterm infant: pathology and mechanisms. Acta Neuropathol 2017;134:331-49.

16 Inder TE, Huppi PS, Warfield S, et al. Periventricular white matter injury in the premature infant is followed by reduced cerebral cortical gray matter volume at term. Ann Neurol 1999:46:755-60.

17 Volpe JJ. Brain injury in premature infants: a complex amalgam of destructive and developmental disturbances. Lancet Neurol 2009:8:110-24.

18 Van Kooij BJM, Benders MJNL, Anbeek P, et al. Cerebellar volume and proton magnetic resonance spectroscopy at term, and neurodevelopment at 2 years of age in preterm infants. Dev Med Child Neurol 2012;54:260-6.

19 Monson BB, Anderson PJ, Matthews LG, et al. Examination of the pattern of growth of cerebral tissue volumes from hospital discharge to early childhood in very preterm infants. JAMA Pediatr 2016;170:772-9.

20 Blok CA, Kersbergen KJ, van der Aa NE, et al. Unmyelinated white matter loss in the preterm brain is associated with early increased levels of end-tidal carbon monoxide. PLoS One 2014:9:e89061.

21 Moeskops P, Benders MJNL, Kersbergen KJ, et al. Development of cortical morphology evaluated with longitudinal $\mathrm{Mr}$ brain images of preterm infants. PLoS One 2015;10:e0131552.

22 Hansen-Pupp I, Hövel H, Hellström A, et al. Postnatal decrease in circulating insulinlike growth factor-I and low brain volumes in very preterm infants. J Clin Endocrinol Metab 2011:96:1129-35.

23 Hansen-Pupp I, Hövel H, Löfqvist C, et al. Circulatory insulin-like growth factor-I and brain volumes in relation to neurodevelopmental outcome in very preterm infants. Pediatr Res 2013:74:564-9.

24 Steinhorn R, McPherson C, Anderson PJ, et al. Neonatal morphine exposure in very preterm infants-cerebral development and outcomes. J Pediatr 2015;166:1200-7.

25 Thompson DK, Warfield SK, Carlin JB, et al. Perinatal risk factors altering regional brain structure in the preterm infant. Brain 2007:130:667-77.

26 Stiver ML, Kamino D, Guo T, et al. Maternal Postsecondary education associated with improved cerebellar growth after preterm birth. J Child Neurol 2015;30:1633-9.

27 Tam EWY, Chau V, Ferriero DM, et al. Preterm cerebellar growth impairment after postnatal exposure to glucocorticoids. Sci Trans/ Med 2011;3:105ra.

28 Kamino D, Studholme C, Liu M, et al. Postnatal polyunsaturated fatty acids associated with larger preterm brain tissue volumes and better outcomes. Pediatr Res 2018:83:93-101.

29 Parikh NA, Lasky RE, Kennedy KA, et al. Perinatal factors and regional brain volume abnormalities at term in a cohort of extremely low birth weight infants. PLoS One 2013;8:e62804.

30 Ekblad M, Korkeila J, Parkkola R, et al. Maternal smoking during pregnancy and regional brain volumes in preterm infants. J Pediatr 2010;156:185-90.

31 Vasu V, Durighel G, Thomas EL, et al. Preterm nutritional intake and MRI phenotype at term age: a prospective observational study. BMJ Open 2014;4:e005390.

32 Thompson DK, Kelly CE, Chen J, et al. Early life predictors of brain development at term-equivalent age in infants born across the gestational age spectrum. Neuroimage 2019; 185:813-824

33 Tolsa CB, Zimine S, Warfield SK, et al. Early alteration of structural and functional brain development in premature infants born with intrauterine growth restriction. Pediatr Res 2004:56:132-8.

34 Gui L, Loukas S, Lazeyras F, et al. Longitudinal study of neonatal brain tissue volumes in preterm infants and their ability to predict neurodevelopmental outcome. Neuroimage 2019;185:728-41.

35 Padilla N, Alexandrou G, Blennow M, et al. Brain growth gains and losses in extremely preterm infants at term. Cereb Cortex 2015;25:1897-905.

36 Vasileiadis GT, Gelman N, Han VKM, et al. Uncomplicated intraventricular hemorrhage is followed by reduced cortical volume at near-term age. Pediatrics 2004;114:e367-72

37 Jeong HJ, Shim S-Y, Cho HJ, et al. Cerebellar development in preterm infants at Term-Equivalent age is impaired after low-grade intraventricular hemorrhage. J Pediatr 2016;175:86-92.

38 Tam EWY, Ferriero DM, Xu D, et al. Cerebellar development in the preterm neonate: effect of supratentorial brain injury. Pediatr Res 2009:66:102-6.

39 Makropoulos A, Counsell SJ, Rueckert D. A review on automatic fetal and neonatal brain MRI segmentation. Neuroimage 2018;170:231-48.

40 Hüppi PS, Warfield S, Kikinis R, et al. Quantitative magnetic resonance imaging of brain development in premature and mature newborns. Ann Neurol 1998;43:224-35. 